\title{
USO DA TÉCNICA DE BRAINSTORMING PARA TOMADA DE DECISÕES NA EQUIPE DE ENFERMAGEM DE SAÚDE PÚBLICA.
}

THE USE OF BRAINSTORMING TECHNIQUE FOR DECISION MAKING IN PUBLIC HEALTH NURSING TEAM.

\section{Maria de Magdala Nóbrega ${ }^{1}$ \\ David Lopes Neto ${ }^{1}$ \\ Sérgio Ribeiro dos Santos ${ }^{2}$}

RESUMO: O estudo enfoca o uso da ferramenta "brainstorming" ou "tempestade de idéias" para a tomada de decisões consensuais no serviço de enfermagem. Desenvolveu-se uma pesquisa qualitativa, com o emprego da técnica de grupo focal envolvendo 06 funcionários de uma unidade básica de saúde do município de João Pessoa, pertencente à rede estadual da Secretaria Estadual de Saúde da Paraíba. Os resultados evidenciaram a viabilidade da aplicação do método como estratégia para a melhoria da qualidade dos serviços de enfermagem.

UNITERMOS: Enfermagem - Administração participativa - Qualidade nos serviços.

ABSTRACT: The study focuses on the use of brainstorming tool for consensual decision making in nursing services. A qualitative research has been developed with focus group technique use involving 6 workers from a basic health unit in Joao Pessoa city which belongs to the state network of Paraíba State Health Secretary. The results showed the method application plausibility as a strategy to nursing services quality improvement.

KEYWORDS: Nursing - Participative administration - Quality in services.

1 Enf̣ermeiros. Alunos do Curso de Mestrado em Enfermagem em Saúde Pública. CCS/UFPB.

2 Enfermeiro/Administrador. Professor Assistente do Departamento de Enfermagem-DEMCA ICCS/UFPB. 


\section{INTRODUÇÃO}

As profundas mudanças que vêm ocorrendo no mundo inteiro têm refletido consideravelmente nas diferentes ciências que direcionam o pensar e o fazer do homem. Essas transformações se interrelacionam, particularmente com a questão do relacionamento humano. O processo histórico-evolutivo da Ciência da Administração revela ganhos incomensuráveis surgidos com a Escola da Administração Científica de Taylor e seqüenciada pelas escolas do processo administrativo, da ciência do comportamento $e$, nas últimas décadas, da administração estratégica e prospectiva com enfoque na qualidade total ${ }^{2}$.

As perspectivas da qualidade em saúde têm se constituido numa palavra de ordem relevante no cenário político-institucional como atributo necessário à produção de serviços com qualidade. Portanto, procurou-se neste estudo focalizar o uso da ferramenta brainstorming na tomada de decisões em equipe, visando apresentá-la como técnica viabilizadora de soluções de problemas na administração dos serviços de enfermagem de saúde pública.

\section{REFERENCIAL TEÓRICO}

A célula mater da administração participativa surgiu com os trabalhos de Peter Ferdinand Drucker, na década de 50 . Em meio às conturbações politicosócio-econômicas da época, novas tendências gerenciais foram estruturadas e sendo aplicadas com o fito à geração de uma maior competitividade, produtividade e qualidade nas empresas ${ }^{8}$.

Consoante o mesmo autor, a administração participativa, apesar de ter como essência a qualidade dos resultados (produtos e serviços), também age através da qualidade do próprio processo administrativo, facilitando o desempenho e auferindo lucro nas instituições.

$\mathrm{Na}$ enfermagem, a administração participativa é um processo impulsionador da qualidade da assistência de enfermagem prestada, como estratégia estabelecedora de padrões (motivação, liderança, trabalho em equipe) que garantam a obtenção da qualidade total nos serviços.

Estudos de Ciampone \& Kurcgant ${ }^{7}$ descrevem que ainda próximo ao século XXI a enfermagem desenvolve uma administração centralizadora e autocrática. Perante os resultados evidenciados, as autoras apresentaram um modelo gerencial denominado administração participativa em enfermagem, o qual é visto como uma nova tendência de gerência dos serviços de saúde, de proporções inovadoras, motivadoras e de trabalho em equipe.

Para Chiavenato ${ }^{6}$, o trabalho em equipe é configurante de uma administração participativa, cujo processo envolve gerente e demais funcionários num clima de envolvimento mental, emocional, motivacional e de aceitação de responsabilidade. Afirma ainda que a administração participativa tem sido apontada como a alavanca para o progresso das instituições, cujas bases estão pautadas na democracia consensual das pessoas envolvidas, prevalecendo, 
para os resultados das negociações, as diferentes expressões de idéias e sugestões expostas num trabalho de discussão em grupo.

Embora existam múltiplas ferramentas científicas de abordagem analítica de melhoria de processo, há algumas que facilitam a condução de reuniões e ajudam a exploração de idéias e tomada de decisões ${ }^{10}$.

Neste sentido, o paradigma administrativo da Gestão da Qualidade Total desenha o "mapa da qualidade" para que se possa atingir um alto grau de desempenho. Segundo Carr, Littman ${ }^{4}$, qualquer pessoa da organização pode utilizar as ferramentas para atingir um bom nivel de desempenho, descobrir oportunidades de melhoria, entender as causas básicas dos problemas e apresentar informações.

A obtenção de informações advindas de um grupo institucional, além de eliminar as barreiras estruturais de uma organização de conduta não laissezfaire, permite a participação de pessoas no processo decisório na solução de problemas. A aplicação de técnicas de grupo, tais como brainstorming, votação múltipla, técnica de grupo nominal e outras, permite que os funcionários demonstrem suas capacidades criativas sem restrição de suas idéias, o que geralmente resulta em soluções concretas dos problemas apresentados nas reuniões.

A sessão brainstorming, por ser uma técnica de grupo, tem por objetivo coletar idéias de todos os participantes, sem críticas ou julgamentos. Logo, destina-se ao recolhimento de idéias e sugestões viabilizadoras de soluções para determinados problemas ou situações de trabalho improdutivo'.

Metodologicamente, o processo de brainstorming segue as seguintes fases:

$1^{\text {a }}$ Fase: Criativa - os participantes da sessão apresentam o maior número de idéias e sugestões sem se preocuparem em analisá-las ou criticá-las;

$2^{\mathrm{a}}$ Fase: Crítica - os participantes da sessão, individualmente, justificam e defendem suas idéias com o propósito de convencerem o grupo; é a fase de filtração de idéias para a permanência das que foram melhor fundamentadas e de aceitação do grupo.

A sessão brainstorming inicia quando o coordenador (moderador e harmonizador dos trabalhos) clarifica a sua função e a do secretário (registrador, organizador e reapresentador das contribuições dos participantes), faz exposição e debate do assunto e define o objetivo a ser conquistado a partir das contribuições apresentadas ao final da reunião ${ }^{1}$.

Lopes Neto, Santos ${ }^{9}$ afirmam que o repasse de novos conhecimentos é necessário entre os membros que compõem a equipe de enfermagem e que o enfermeiro, um agente de mudança no setor da saúde, deve buscar alternativas flexíveis e humanisticas para a resolução de problemas que atingem os serviços. 


\section{MATERIAL E MÉTODO}

Trata-se de um estudo qualitativo, com o emprego da técnica brainstorming para o conhecimento de situações-problemas direcionados à administração dos serviços de enfermagem de saúde pública.

A pesquisa realizou-se em um Centro de Saúde do município de João Pessoa, da rede básica da Secretaria Estadual de Saúde da Paraíba, no mês de setembro de 1995. O universo populacional foi composto por 17 funcionários do turno vespertino lotados na referida unidade. A amostra constituiu-se de 06 servidores que aceitaram em participar da pesquisa.

Para a condução da sessão de brainstorming, estabeleceu-se as seguintes regras: (1) o participante deve sentir-se livre e à vontade; (2) não é permitida a rejeição de idéias; 3 não deve haver discussões durante a fase criativa da sessão; (4 não são permitidas críticas ou julgamentos pessoais na segunda fase; 5 as idéias serão expostas em um flip chart para melhor visualização e participação do grupo.

Após a sessão em suas distintas etapas (criativa e crítica), os resultados foram filtrados, permanecendo os que melhor fundamentaram as idéias ao nivel de consenso da equipe.

\section{ANÁLISE E DISCUSSÃO DOS RESULTADOS}

Durante a sessão de brainstorming, o grupo em estudo expôs inúmeros problemas e sugestões de resolutividade para os mesmos. Diante das situações apresentadas, referencia-se abaixo, antes de ser apresentado o resultado da aplicação da técnica, a que evidencia o serviço de enfermagem e a mais referida pelos participantes durante a sessão com 0 intuito de respaldá-las cientificamente, principalmente a de competência exclusiva do enfermeiro.

\section{a) Consulta de Enfermagem}

A consulta de enfermagem é um instrumento legitimado como atividade privativa do enfermeiro a partir de 1986, pela legislação do exercício profissional da enfermagem (Lei n. ${ }^{\circ} 7.497 / 86$ ) e regulamentada pelo Decreto n. ${ }^{\circ} 94.406 / 86$, caracterizando a sua autonomia profissional enquanto trabalhador liberal ${ }^{3}$

\section{b) Resíduos dos serviços de saúde (lixo ambulatorial)}

As agências nacionais e internacionais de saúde, referendadas por pesquisas operacionais e bibliográficas, criaram um modelo de classificação de todos os resíduos produzidos em serviços de saúde com o objetivo de se atingir os niveis adequados de controle e segurança que vêm sendo preconizados pela Organização Mundial de Saúde - $\mathrm{OMS}^{5}$. Neste contexto, o poder público, representado por agências estaduais e municipais de saúde, tem a responsabilidade de garantir a saúde pública, a qualidade de vida do trabalhador e a preservação do meio ambiente apresentando ações que solucionem a destinação final dos resíduos dos serviços de saúde, cabendo ainda aos 
municipios receberem incentivos técnicos e financeiros através das instituições de saúde (Vigilância Sanitária) para a prestação do tratamento especial exigido pelo lixo hospitalar ou ambulatorial.

Tomando-se por base a aplicação da técnica brainstorming em suas distintas fases, o estudo apresentou os seguintes resultados:

\begin{tabular}{|c|c|}
\hline FASE CRITICA & FASE CRIATIVA \\
\hline SETOR DE ODONTOLOGIA & \\
\hline
\end{tabular}

Falta de material peimanente Foi colocado que o instrumental disponivel não atende à (instrumental odontológico) demanda da unidade, o que compromete o profissional no seu labor e coloca em risco a saúde do cliente.

\section{RECOMENDAÇÕES:}

Prover de material permanente e de consumo, de acordo com as metas estabelecidas pela Secretaria de Estado da Saúde-SES para atendimento diário.

$\Theta$ Repor semanalmente o material de consumo observando as referidas metas.

Esterilização inadequada .

O maior problema quanto à esterilização está na utilização da estufa, pois o não cumprimento das rotinas estabelecidas para esterilização poderá causar danos tanto ao material quanto aos manipuladores e clientes, haja visto que a temperatura necessária para uma perfeita esterilização em estufa é $170^{\circ} \mathrm{C}$ durante 60 minutos, geralmente não é alcançada.

\section{RECOMENDAÇÕES:}

- Providenciar uma sala só para esterilização.

- Capacitar pessoal para trabalhar exclusivamente com esterilização (treinamento em serviço, educação continuada).

Estabelecer normas e rotinas.

Vestuário inadequado de clientes na unidade

A maioria dos profissionais se sentem constrangidos ao atenderem clientes com roupas inadequadas.

\section{RECOMENDAÇÕES:}

Expedir uma norma proibindo o uso de roupas tipo short, bermudas, blusas ou vestidos decotados e transparentes na unidade.

Desenvolver um trabalho educativo junto à comunidade quanto ao modo de se vestir em determinados locais públicos.

Desvio de função

Este problema foi ponto bastante polêmico e debatido na reunião devido à existência de profissionais qualificados para determinada função, mas exercendo uma outra. 


\section{RECOMENDAÇÕES:}

- Levantar os recursos humanos existentes na unidade por qualificação profissional.

- Remanejar funcionário, observando a relação setor da unidade e qualificação profissional.

OBS.: Ressalta-se que na administração participativa os funcionários juntamente com a direção estudarão os métodos mais flexiveis e proporcionadores de satisfação no tocante às tomadas de decisões.

Falta de programa de capacitação de recursos humanos para a unidade

Falta de cronograma de reuniões administrativas e sociais

Falta de integração
Os relatos evidenciaram a inexistência de programas de desenvolvimento de pessoal (capacitação técnica, reciclagem, treinamento em serviço e educação continuada).

- Implantar programas de desenvolvimento de recursos humanos.

Segundo os participantes, as reuniões são marcadas quando surgem alguns problemas, o que compromete a participação da maioria.

\section{RECOMENDAÇÕES:}

- Elaborar um cronograma de reuniões administrativas e sociais, envolvendo a participação de todos os funcionários.

- Delegar competência aos funcionários quanto à organização dos eventos sociais, cabendo-lhes o processo de escolha e formação da equipe.

Tendo em vista a dissociabilidade entre o grupo, em especial no que se refere aos funcionários por turno de trabalho, foi levantada a necessidade de uma maior integração, a qual poderá influenciar positivamente no desempenho das ações.

\section{RECOMENDAÇÃO:}

- Realizar reuniões sociais - aniversariantes do mês, confraternização natalina, festa junina, jogos esportivos, passeios, dinâmicas de grupo.

\section{SETOR DE FARMÁCIA}

Desorganização e descontinui- Neste setor inexiste sistematização e continuidade dos dade dos serviços serviços. Pressupõe-se que este problema esteja relacionado com a presença de funcionários com desvio de função e pela não elaboração de normas administrativas internas, atribuidoras de funções e responsabilidades aos funcionários por respectivos setores. 
Escassez de recursos humanos

\section{SETOR DE RECEPÇÃO}

RECOMENDAÇÕES:

- Remanejar pessoal qualificado.

Treinar recursos humanos para o setor

- Expedir normas administrativas delegando responsabilidades aos funcionários do setor por turnos.

- Solicitar junto à SES contratação de farmacêutico ou a presença de um farmacêutico supervisor, pelo menos quinzenalmente na unidade.

Este item foi contemplado unanimente pelos participantes devido à defasagem de pessoal na unidade em nivel qualitativo e quantitativo.

\section{RECOMENDAÇÕES:}

- De acordo com a filosofia, objetivos e metas da SES, em particular referente ao Centro de Saúde em estudo, realizar um levantamento quanti-qualitativo dos recursos humanos disponiveis.

- Caracterizar a clientela de acordo com os programas implantados, especialidades profissionais e recursos materiais disponiveis.

- Aplicar cálculos de pessoal apropriados para cada setor da unidade.

Falta de recursos materiais $\mathrm{O}$ problema está relacionado com a superlotação do arquivo permanentes (arquivo) e de de fichas existentes no setor, o que tem dificultado o bom consumo (fichas) andamento do serviço. A falta de fichas de atendimento ao cliente no local é outro problema citado pelos funcionários e que também interfere no serviço.

\section{RECOMENDAÇÕES:}

- Aplicar recursos financeiros na informatização do serviço.

- Adquirir material permanente para arquivo.

- Prover semanalmente o setor de recepção com fichas, delegando responsabilidades aos funcionários por turno, quanto à prestação de contas do material recebido. Exemplo: número de clientes novos (fichas novas) + número de fichas restantes + saldo de fichas da semana anterior + total de fichas recebidas.

Desvio de função Ver item referente anteriormente citado

\section{SETOR DE ENFERMAGEM}

Falta de retorno da SES após Os participantes queixaram-se da falta de retorno dos supervisão serviços - SES, quando das supervisões realizadas para a deteç̧ão de problemas e levantamento de necessidades do serviço, ficando as propostas apenas em relatórios.

\section{RECOMENDAÇÕES:}

- Solicitar aos técnicos da SES que, ao realizarem a supervisão, apresentem soluções aos problemas detectados e necessidades levantadas, para o perfeito desenvolvimento do serviço. 
Dificuldade para realizar consultas de enfermagem
Segundo as enfermeiras, vários fatores contribuem para a não operacionalização das consultas de enfermagem: falta de capacitação de pessoal para o atendimento especifico à criança e à gestante; número insuficiente de profissionais de enfermagem; o desenvolver multitarefas; falta de triagem da clientela e a falta fluxograma de atendimento.

\section{RECOMENDAÇÕES:}

Nomatizar a triagem na unidade desenvolvida por um enfermeiro e um auxiliar ou técnico de enfermagem, observando-se o fluxograma de atendimento e necessidades gerais do cliente.

$\theta$ Introduzir a consulta de enfermagem, a partir de estudos realizados pelas próprias enfermeiras da unidade, quanto ao número de cliente/dia por programa implantado.

- Sugerir à SES a contratação e/ou remanejamento de pessoal de enfermagem para a unidade, visando a implantação de novos programas de saúde e dos existentes.

Presença de material permanente Foi relatada a presença de corrosão e sujidade em materiais deteriorado

Inacessibilidade à água potável

Inadequada coleta de lixo ambulatorial acondicionada dentro de um tanque sem que haja permanentes, o que toma o local insalubre, principalmente no que se refere ao desenvolvimento de intervenções de enfermagem, consultas médicas, atendimentos odontológicos e de outros profissionais devido a possivel concentração de agentes patogênicos nestes fômites.

\section{RECOMENDÇŐES:}

Observar rotineiramente as superfícies, equipamentos e material permanente e de consumo que possam comprometer a saúde dos clientes e dos profissionais.

- Providenciar, quando da detecção de qualquer produto impróprio na unidade, a sua remoção ou a reposição e destinação do objeto danificado.

O problema reside na distribuição de água para beber. Segundo os funcionários, a água servida nas tomeiras não está dentro dos padrões de potabilidade, pois a mesma é manutenção periódica.

\section{RECOMENDAÇÃO:}

Providenciar a manutenção periódica do reservatório de água e adquirir garrafões de água mineral com os suportes térmicos, colocando-os em lugares de fácil acesso a todos os funcionários da unidade.

Os funcionários salientaram que os resíduos da unidade são coletados como lixo domiciliar, fator este que coloca em risco a saúde da comunidade por se tratar de resíduos de saúde (contaminados).

\section{RECOMENDAÇÃO:}

Solicitar às agências estaduais e municipais de saúde (Vigilância Sanitária) que operacionalizem a devida destinação do lixo proveniente dos serviços de saúde ambulatóriais, objetivando o cumprimento das normas contidas na legislação recomendada pela OMS. 


\section{CONCLUSÃO}

O desenvolvimento da "ferramenta brainstorring" ou "tempestade de idéias", neste estudo teve a participação de quatro setores do centro de saúde, onde observou-se a sua eficácia e viabilidade, através dos problemas apresentados na fase criativa pelos participantes, como também das recomendações feitas e aceitas pelos mesmos, na fase crítica, em busca de melhores condições de trabalho, tanto para os profissionais como para a clientela atendida.

Essa técnica proporciona a identificação de uma variedade de problemas que podem ser solucionados juntamente com funcionários e direção do referido estabelecimento, trazendo, assim, alto grau de resolutividade na busca da melhoria contínua da qualidade.

Espera-se que este trabalho venha contribuir no gerenciamento do serviço de enfermagem, não só no local do estudo mas também para os demais centros de saúde que procuram o caminho da administração participativa, fazendo com que os funcionários sejam parceiros e co-responsáveis pela qualidade do serviço de saúde.

\section{REFERÊNCIAS BIBLIOGRÁFICAS}

1. ABREU, Romeu Carlos Lopes de. CCQ, Círculos de Controle de Qualidade: Integração-Trabalho-Homem-Qualidade Total. 2. ed. Rio de Janeiro: Qualitymark, 1991. p. $175,176$.

2. ALARCÓN, Nelly Garzón. Conferencia: la administración de enfermería en america latina. In: R. Paul. Enf., v. 10, n. 2, p. 55, mai./ago.1991.

3. CAMPEDELLI, Maria Coeli. Processo de enfermagem na prática. São Paulo: Ática, 1989. p. 128-130.

4. CARR, David K., LITTIMAN, lan D. Excelência nos serviços públicos: gestão da qualidade total na década de 90. Rio de Janeiro: Qualitymark, 1992. p. 78,79.

5. CENTRO DE VIGILÂNCIA SANITÁRIA. Sistema Único Descentralizado de Saúde de São Paulo. Subsídios para organização de sistemas de resíduos em serviços de saúde. São Paulo: CVS, 1989. p. 9.

6. CHIAVENATO, Idalberto. Gerenciando pessoas: o passo decisivo para a administração participativa. São Paulo: Makron Books, 1992. p. 
7. CIAMPONE, Maria Trench, KURCGANT, Paulina. Administração Participativa: considerações sobre sua aplicabilidade nos serviços de enfermagem. In: $R$. Enfoque, São Paulo, v. 17, n. 2, p. 34, jan. 1989.

8. HOLLAND, Neila Anchieta. O modelo POQ: a administração participativa a caminho da qualidade. Rio de Janeiro: Qualitymark, 1993. p. 27,28.

9. LOPES NETO, David, SANTOS, Sérgio Ribeiro. Técnicas gráficas de solução de problemas para a excelência na enfermagem: uma abordagem teórica. In: R. O Mundo da Saúde, v.19, n. 2, mar. 1995. p. 74

10. SCHOLTES, Peter R. Times da qualidade: como usar equipes para melhorar a qualidade. Rio de Janeiro: Qualitymark, 1992. p. 37. 